San Jose State University

From the SelectedWorks of Marjorie R. Freedman

March, 2010

\title{
School Health Fairs Show Potential to Improve Short-term Learning
}

Marjorie R. Freedman, San Jose State University

\section{(c) (i) $\Theta$}

This work is licensed under a Creative Commons CC_BY-NC-ND International License.

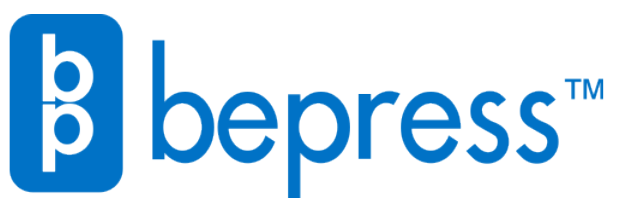

Available at: https://works.bepress.com/marjorie_freedman/20/ 


\title{
School Health Fairs Show Potential To Improve Short-Term Learning
}

\author{
Marjorie R. Freedman \\ Journal of Nutrition Education and Behavior \\ INTRODUCTION
}

School based health fairs, that include a variety of informational and/or "fun" booths, are examples of Level 1 interventions designed to build awareness of a health or nutritional topic or problem (1). Designing, implementing and evaluating a health fair utilizes considerable

resources. Yet, recent examination of their efficacy in increasing knowledge is limited (2-4). No research has been conducted on pre-adolescents, a group whose patterns of behavior and food choices may affect their current and future health status. Currently, almost one-third of children and adolescents aged 2 to 19 are overweight or obese (5). Fewer than $10 \%$ of females and $25 \%$ of males aged 9 to 13 years old meet calcium requirements (6). This project developed and evaluated a one-day health fair aimed at increasing knowledge relating to healthful eating and physical activity in a multiethnic group (43\% Caucasian, $42 \%$ Asian, and $12 \%$ Hispanic) of preadolescents attending a large, suburban middle school.

\section{PROGRAM DESCRIPTION AND IMPLEMENTATION}

School district health employees partnered with a nutrition professor at a local university to develop a health fair curriculum based on social cognitive theory. Prior to attending the fair, $6^{\text {th }}$ grade students completed a 5-minute, 13-question multiple-choice exam during physical education (PE) class. Each question had a "do not know" choice to eliminate guessing. One week later, students attended the health fair during their 40-minute PE class. Post-tests were completed 5-7 days later.

On the day of the fair, PE instructors divided their classes into groups of 12-18 students, who together rotated through each of 5 stations manned by volunteers, including school nurses, dietitians, a representative from the local dairy council, and community nutrition students from a local university. All volunteers received copies of the test questions prior to the fair to ensure main learning objectives were addressed.

Learning stations were set up on 6-foot long tables in the school gymnasium. Participatory curriculum and visual aids were used to convey information. The goal of station 1 was to increase knowledge about obesity in adolescents, the sugar and caffeine content of beverages, and to help students understand food labels. Materials were adapted from the Bay Area Nutrition and Physical Activity Collaborative (BANPAC) "Soda Free Summer" campaign (7). Using empty beverage bottles, students learned how to convert grams of sugar (indicated on the food label) into teaspoons of sugar. After calculating the amount of sugar in each bottle, they were shown clear plastic zip-lock bags containing the correct amounts in teaspoon measures. The "fizzics of soda" display was used to prompt a brief discussion of sugar intake, calories, and obesity. Students ranked energy drinks from highest to lowest in caffeine content.

Station 2 aimed to increase knowledge on calcium and dairy intake. Jars filled with flour, illustrating the relative amount of calcium in bones of children, adolescents, adults and the elderly, were displayed. The dairy council volunteer conveyed the importance of adequate 
calcium intake during adolescence to the development of peak bone mass, and educated students about dairy and non-dairy sources of calcium. Station 3 focused on portion size and healthful eating. Using common items (e.g., a deck of cards, baseball, dice, CD, and hockey puck), students visualized recommended portion sizes. All read nutrition labels to determine total number of calories based on number of servings.

Station 4 displayed food items purchased from a local fast food restaurant. Students discussed what constitutes a healthful balanced meal, how to make appropriate fast food restaurant choices, and how to avoid "supersized" portions. Station 5 explored energy balance and physical activity. Students discussed the benefits of physical activity and were told the recommended amount was 60 minutes/day. They were then guided through a series of jumping jack exercises as a lead-in to the discussion of energy balance.

\section{EVALUATION}

Pre- and posttests were completed by 267 students. Data were analyzed using SPSS version 16.0 for Mac (SPSS, Chicago, IL, 2008). Paired-sample $t$ tests determined differences for normally distributed data, and Wilcoxon signed ranks were used for non-normally distributed data. Results indicated knowledge significantly increased following health fair attendance $(\mathrm{P}<$ $.001)$. Total scores improved from $50 \%( \pm 18.6)$ to $61 \%( \pm 19.0)$ correct, with significant improvement on 9 of 13 questions. Significantly more students were able to identify yogurt, broccoli, and tofu as foods containing calcium, and to identify a well-balanced breakfast (a $21 \%$ and $13 \%$ increase, respectively). Significantly more learned that obesity rates had tripled in U.S. children since 1980, that the average daily sugar intake of Americans is .5 lb/day, that preadolescents should exercise for at least 60 minutes/day, and that physical activity has numerous health benefits (a 33\%, 18\%, 12\% and 8\% increase, respectively). There were no pre-post differences in the percentages of students able to answer questions that involved calculations (e.g., calculating total calories and grams of sugar in a drink with 2.5 servings). This indicates that students with correct answers approached these questions as math problems, and were able to perform necessary calculations independent of exposure to the health fair.

\section{CONCLUSION}

Health fairs continue to be popular methods to disseminate nutrition information in school settings. Though they appear to be effective in increasing knowledge among preadolescents in the short-term, results indicate continued room for improvement. Outcomes may be improved by increasing individuals' exposure to the material (which was limited, in this study, by large class size and limited station time). Long-term retention of knowledge was not assessed, and translation of knowledge into behavior change cannot be implied. However, this study suggests that health fairs are effective ways to teach nutrition information to preadolescents, and should be part of overall comprehensive approaches to nutrition education in school settings.

\section{NOTES}

The San José State University Institutional Review Board for human subjects approved this research. Materials used at the health fair can be purchased from local fast food restaurants, assembled from inexpensive materials (e.g. empty soda bottles, sugar, flour, jars), or ordered

Freedman_Health Fairs 
from www.eNasco.com/nutrition. The author would like to acknowledge Thea Roberts Lynch for her help with data entry and Susan Aldrich, RN for help with program planning and implementation.

\section{REFERENCES}

1. O'Donnell M. Definition of health promotion: Part II: levels of programs. Am J Health Promot. 1986;1:6-9.

2. Bhagat R, Shuster S. Preschool health fairs. Can Nurse. 1995;91:49-50.

3. Igoe, J. An update on student health fairs. Pediatric Nursing. 1991;17:170-172.

4. Carter K. The health fair as an effective health promotion strategy. AAOHN J. 1991;39:513516.

5. Ogden CL, Carroll MD, Curtin LR, McDowell MA, Tabak CJ, Flegal KM. Prevalence of overweight and obesity in the United States, 1999-2004. JAMA. 2006;295:1549-1955

6. Moshfegh A, Goldman J, Cleveland L. What We Eat in America, NHANES 2001-2002: Usual Nutrient Intakes from Food Compared to Dietary Reference Intakes. Beltsville MD: US Department of Agriculture, Agricultural Research Service; 2005.

7. Bay Area Nutriiton \& Physical Activity Collaborative. Sugar Savvy Curriculum. Available at: http://www.banpac.org/resources_sugar_savvy.htm. Accessed March 20, 2009. 